\title{
Avaliação de Dietas para Eqüinos de Uso Militar em Atividade Física Moderada ${ }^{1}$ \\ Patrícia Maia Galvão², Fernando Queiroz de Almeida ${ }^{3}$, Chiara Albano de Araújo Oliveira², José Roberto Pinto de Andrade Lima ${ }^{4}$, Antônio Assis Vieira ${ }^{5}$, Bruna Adese ${ }^{6}$, Tiago Marques dos Santos ${ }^{6}$
}

\begin{abstract}
RESUMO - Objetivou-se, com o presente trabalho, avaliar dietas de cavalos de uso militar em atividade física moderada. O experimento foi realizado no Regimento Escola de Cavalaria do Exército Brasileiro, onde foram avaliadas as dietas dos eqüinos do Esquadrão de Cerimonial. No ensaio de desempenho, foi utilizado delineamento experimental em blocos casualizados, compostos de três tratamentos, sendo o bloco a idade dos animais e os tratamentos, as dietas experimentais. Na dieta I, quinze animais receberam dietas com ração comercial com feno de alfafa e coastcross incorporados ao pelete; na dieta II, quinze animais receberam ração comercial peletizada e, na dieta III, quatorze animais receberam ração comercial peletizada semelhante à dieta II, acrescida de 3,0 kg de aveia hidropônica. Em todas as dietas, foram adicionados 3,0 kg de feno de coastcross. Em seguida, foi conduzido o ensaio de digestão em delineamento inteiramente casualizado, com os três tratamentos supracitados e quatro repetições, além da coleta total de fezes, para avaliação da digestibilidade dos nutrientes das dietas experimentais. Os valores obtidos foram submetidos à análise de variância e as médias, comparadas pelo teste de Tukey, a 5\% de probabilidade. Os animais alimentados com as dietas experimentais tiveram o peso vivo e escore corporal inalterados pelas variações dos conteúdos de nutrientes das mesmas. Os coeficientes de digestibilidade foram afetados pela dietas experimentais e, de acordo com os resultados observados, a dieta contendo ração comercial com feno incorporado ao pelete, mostrouse mais digestível. O consumo de energia e proteína digestível nas dietas avaliadas foi adequado às atividades militares e o consumo de fibra dietética (expressa em FDN e FDA) foi adequado às recomendações mínimas necessárias para os eqüinos.
\end{abstract}

Palavras-chave: cavalos, dietas, energia digestível, proteína digestível

\section{Evaluation of Diets for Military Horses in Moderate Activity}

\begin{abstract}
This study aims to evaluate diets for military horses in moderate activity. This experiment was conducted at Cavalry School of Brazilian Army where diets for horses of Ceremonial Squadron was evaluated. Diets were composed by commercial concentrate, Coast-cross grass hay and hydroponic oat. An performance trial in an randomized block design with three blocks (age of animals) and three treatments (experimental diets) were used. Diet I, fifteen horses fed diets composed by commercial concentrate with alfalfa hay into the pellets; Diet II, fifteen animals fed diets composed by commercial concentrate pellets; Diet III, fourteen animals fed diets composed by commercial concentrate pellets plus $3.0 \mathrm{~kg}$ hydroponic oat. Three kilograms of Coast-cross grass hay were added in all diets. At the end of this trial, a digestion trial was carried, in a complete randomized design, with three treatments (diets) and four replications (animals) to evaluate digestibility nutrients of diets, according total feces collection method. Values were submitted by variance analysis and means compared by Tukey test at $5 \%$ probability. Animals fed experimental diets maintained body weight and corporal score without any change according to nutrients contents in the diets. The coefficients digestibility of nutrients were changed in function of the diets and experimental diet composed by commercial concentrate with alfalfa hay into the pellets were more digestible. Intake of digestible energy and protein were adequate to military horses in moderate activity. Intake of dietetic fiber as NDF and ADF were adequate to minimum recommendations for horses.
\end{abstract}

Key Words: diets, digestible energy, digestible protein, horses

\footnotetext{
1 Parte da Dissertação do primeiro autor apresentada ao Programa de Pós-Graduação em Zootecnia da UFRRJ.

2 Zootecnista. Discente de Mestrado em Zootecnia da UFRRJ (pgalvao@ufrrj.br; oliveirachiara@yahoo.com.br).

3 Professor Adjunto da UFRRJ. Bolsista de Produtividade em Pesquisa CNPq (falmeida@ufrrj.br).

Correspondência: DMCV-IV-UFRRJ. BR 465, km 7, Seropédica, RJ. CEP: 23890-000.

${ }_{4}^{4}$ Oficial Veterinário. Regimento Escola de Cavalaria do Exército Brasileiro. Rio de Janeiro, RJ (jose_roberto70@hotmail.com)).

5 professor Adjunto. DPA-IZ-UFRRJ, Seropédica, RJ BR 465, km 7, Seropédica, RJ. CEP: 23890-000 (aassisv@ufrrj.br).

${ }^{6}$ Discente de Graduação da UFRRJ. Bolsista PIBIC/CNPq-UFRRJ (tiago-mt@bol.com.br).
} 


\section{Introdução}

Entre os nutrientes necessários ao bom desempenho do eqüino atleta, a energia é de fundamental importância, uma vez que é o fator nutricional mais influenciado pelo esforço físico quando se considera a quantidade de energia, fonte $\mathrm{e}$ tempo de fornecimento da dieta (Hintz, 1997). A energia dietética é suprida por fontes energéticas, como carboidratos solúveis, celulose, pectinas, hemiceluloses, gorduras e proteínas, e o valor energético da matéria-prima dependerá da proporção entre substratos solúveis e fermentáveis que ela contiver.

São quatro as principais formas para descrever o potencial energético dos alimentos ou das dietas para os eqüinos: nutrientes digestíveis totais (NDT), energia digestível (ED), energia metabolizável (EM) e energia líquida (EL). Cada forma é descrita em diversos sistemas ao longo dos anos, sendo o NDT a menos utilizada atualmente. O NRC (1989) recomenda o uso de energia digestível nas estimativas das exigências energéticas, por conter maior número de dados experimentais disponíveis. Estes valores são obtidos por meio de equações que consideram o peso do animal e o nível de trabalho para animais adultos em desenvolvimento de atividade atlética ou em mantença.

As exigências energéticas variam de forma significativa entre os eqüinos. O peso vivo e a condição corporal podem ser usados como referenciais para se adequar a ingestão de energia. É importante determinar a quantidade de dieta necessária para um animal alcançar suas exigências energéticas, pois o nível de ingestão irá indicar a concentração dos outros nutrientes; portanto, as dietas dos cavalos não podem ser formuladas sem o conhecimento de seus conteúdos energéticos (Pagan, 2000a).

Os eqüinos em atividades de tração, equitação, corrida e salto realizam trabalho muscular e, nos diversos grupos de atividades esportivas, a intensidade e duração do trabalho são diferentes. O tipo de trabalho exige alterações na formulação e no fracionamento da dieta (Meyer, 1995).

A energia necessária para realização do trabalho atlético é suprida pelo armazenamento de glicogênio e triglicerídeos nos tecidos muscular e adiposo e de glicogênio no tecido hepático. As rotas e os substratos usados para produção de intermediários químicos usados como combustível para a contração muscular durante o exercício dependem da intensidade e duração do exercício, da velocidade, do condicionamento físico, da composição muscular do animal, do tipo de alimento fornecido ao animal e da idade do mesmo (Pagan, 2001). Diferenças no metabolismo energético dos equiinos nas diversas modalidades esportivas nos mostram que, dependendo do tipo de exercício estabelecido, o manejo alimentar de animais de competição deve ser modificado.

A idade e a atividade do eqüino são considerações importantes na determinação das exigências protéicas, além de outros fatores destacáveis acerca da proteína que devem ser avaliados ao selecionar uma dieta para determinada fase da vida do cavalo. Entre os principais, estão a digestibilidade da proteína, o conteúdo em aminoácidos e a relação de proteína/ energia da dieta (Pagan, 2000b).

Segundo Hiney \& Potter (1996), as exigências de proteína dietética para eqüinos adultos são baixas, em comparação às daqueles em crescimento, sugerindo níveis de 11 a $12 \%$ de proteína bruta em dietas para equiinos em atividade atlética. Os autores ressaltam que o excesso de proteína pode reduzir o rendimento. O NRC (1989) estima a exigência para mantença de 40 g PB/Mcal ED, recomendação provavelmente muito generosa, posto que as exigências de proteína não aumentam tão rapidamente quanto as de energia para eqüinos em exercício (Pagan, 2000b).

O NRC (1989) sugere o uso da proteína digestível para avaliar as exigências protéicas do cavalo, uma vez que a digestibilidade varia de acordo com a fonte de proteína e sua concentração na dieta.

Objetivou-se, com o presente trabalho, avaliar dietas de eqüinos utilizados para fins militares, em atividade física moderada, por meio da estimativa da digestibilidade aparente dos nutrientes e da avaliação do peso vivo e do escore corporal dos animais.

\section{Material e Métodos}

O trabalho foi conduzido no Regimento Escola de Cavalaria Andrade Neves do Exército Brasileiro, no Rio de Janeiro, RJ, e as análises bromatológicas foram realizadas no Laboratório de Bromatologia do Instituto de Zootecnia da UFRRJ, Seropédica, RJ. $\mathrm{O}$ experimento foi realizado nos meses de janeiro a abril de 2001, período em que, segundo o Ministério da Aeronáutica, a temperatura média local foi de $30^{\circ} \mathrm{C} \mathrm{e}$ a umidade média, de $73,6 \%$.

Os animais foram alojados em baias de alvenaria - com piso de paralelepípedo ou cimento do tipo meia-

R. Bras. Zootec., v.33, n.6, p.1492-1499, 2004 
parede, com frente de $0,80 \mathrm{~m}$, profundidade de $2,0 \mathrm{~m}$ e altura frontal de $1,6 \mathrm{~m}$, elevando-se até $2,0 \mathrm{~m}$ ao fundo - providas de comedouros para ração e feno e bebedouro com $0,30 \mathrm{~m}$ de altura e $0,25 \mathrm{~m}$ de profundidade. $\mathrm{O}$ fechamento da baias foi feito com uma trava de ferro presa à parede por correntes.

Os animais avaliados foram aleatoriamente distribuídos nas baias para os ensaios de desempenho e de digestibilidade. Foram utilizados eqüinos que compunham o Esquadrão Cerimonial, com atividades de representação militar do tipo Carrossel, caracterizada pela atividade física moderada, com duração diária de 1,5 horas, com andamento ao passo, ao trote e ao galope.

Para o ensaio de desempenho, foram selecionados 44 animais das raças Hanoveriano, Brasileiro de Hipismo, Anglo-árabe, Crioulo e seus mestiços, com peso médio de 413,1 $\pm 34,2 \mathrm{~kg}$, altura de cernelha média de 1,6 m, idade média de 9,9 $\pm 4,3$ anos, divididos em três blocos, e submetidos a três tratamentos, que consistiam de diferentes dietas. Os blocos foram distribuídos segundo as idades, de modo que o bloco I foi composto por animais de 4 a 7 anos; o bloco II, por animais de 8 a 12 anos; e o bloco III, por animais de 13 a 21 anos.

O período experimental foi de 90 dias e os animais foram avaliados com base em pesagem mensal e escore corporal, segundo metodologia descrita por Hennecke et al. (1983). Os animais estiveram em exercício diário do tipo moderado, para exibições militares, no período pré-experimental (14 dias), e mantido durante o período experimental.
As dietas foram fornecidas considerando-se um consumo diário de $2,0 \%$ do peso vivo dos animais, com base na matéria seca (kg de alimento/animal/dia), de acordo com as recomendações do NRC (1989), e seguindo a rotina utilizada na Unidade Militar. As dietas foram compostas por feno de capim coastcross como volumoso, fornecido três vezes ao dia (às $4 \mathrm{~h}$, $11 \mathrm{~h} 30$ e 19h), inteiro e no cocho, e de ração concentrada peletizada, fornecida às 5,13 e 20h. Dos 44 eqüinos avaliados, 15 receberam ração comercial peletizada com feno de alfafa e coastcross incorporados ao pelete (Dieta I), 15 animais receberam ração comercial peletizada (Dieta II) e 14, ração comercial peletizada, acrescida de $3 \mathrm{~kg}$ de aveia hidropônica (Dieta III), fornecida às $16 \mathrm{~h}$. O suplemento mineral foi fornecido na quantidade de $30 \mathrm{~g}$ diários.

A aveia hidropônica foi obtida pela germinação do grão de aveia em sala climatizada e com iluminação contínua, onde as sementes ficaram imersas em bandejas com solução nutritiva fornecida por sistema de irrigação.

A composição bromatológica das rações comerciais e dos alimentos volumosos utilizados nas dietas experimentais encontra-se na Tabela 1. A composição das dietas, os teores de energia bruta (EB) e os percentuais de matéria seca (MS), de proteína bruta $(\mathrm{PB})$, de extrato etéreo $(\mathrm{EE})$, de fibra em detergente neutro (FDN) e de fibra em detergente ácido (FDA) são descritos na Tabela 2.

Ao término do ensaio de desempenho, foram sorteados quatro animais de cada tratamento (total de

Tabela 1 - Composição bromatológica das rações concentradas e alimentos utilizados nas dietas experimentais (\% na MS)

Table 1 - Chemical composition of concentrate and feeds used in experimental diets $(\%$ in $D M)$

\begin{tabular}{|c|c|c|c|c|c|c|}
\hline $\begin{array}{l}\text { Ingredientes } \\
\text { Ingredients }\end{array}$ & $\begin{array}{c}\mathrm{EB} \\
\text { (Mcal } / \mathrm{kg}) \\
C E \\
\end{array}$ & $\begin{array}{l}\text { MS } \\
(\%) \\
D M \\
\end{array}$ & $\begin{array}{c}\mathrm{PB} \\
(\%) \\
C P \\
\end{array}$ & $\begin{array}{c}\mathrm{EE} \\
(\%) \\
E E \\
\end{array}$ & $\begin{array}{c}\text { FDN } \\
(\%) \\
N D F \\
\end{array}$ & $\begin{array}{c}\text { FDA } \\
(\%) \\
A D F \\
\end{array}$ \\
\hline $\begin{array}{l}\text { Feno de capim coastcross } \\
\text { Coastcrossgrass hay }\end{array}$ & 4,3 & 91,3 & 5,8 & 1,6 & 77,4 & 39,6 \\
\hline $\begin{array}{l}\text { Ração Hippus } \\
\text { Hippus ration }\end{array}$ & 4,2 & 91,3 & 16,6 & 4,2 & 42,1 & 20,0 \\
\hline $\begin{array}{l}\text { Ração Corcelina } \\
\text { Corcelina ration }\end{array}$ & 3,9 & 91,2 & 13,6 & 3,5 & 46,1 & 10,5 \\
\hline $\begin{array}{l}\text { Aveia hidropônica } \\
\text { Hydroponic oat }\end{array}$ & 4,2 & 11,6 & 15,7 & 4,1 & 54,0 & 28,1 \\
\hline
\end{tabular}

\footnotetext{
${ }^{2}$ Ração Hippus - Agribrands Purina.

${ }^{3}$ Ração Corcelina - Agribrands Purina.
}

R. Bras. Zootec., v.33, n.6, p.1492-1499, 2004 
12), que foram utilizados no ensaio de digestibilidade aparente, feito em delineamento inteiramente casualizado com três tratamentos (dietas) e quatro repetições, sendo cada animal uma unidade experimental. Os coeficientes de digestibilidade aparente dos nutrientes foram estimados pelo método da coleta total de fezes. O ensaio de digestibilidade aparente teve duração de 14 dias - 10 para adaptação às dietas e quatro para coleta total de fezes, período em que os animais foram alimentados nos horários pré-estabelecidos e as quantidades de alimentos e de sobras foram pesadas diariamente.

Os animais permaneceram nas baias durante o período de coleta, caminhando diariamente por cerca de meia hora, devidamente acompanhados e observados para eventual coleta de fezes. As fezes foram coletadas diretamente do piso das baias, por 24 horas, durante quatro dias. Posteriormente, foram armazenadas em baldes de plástico, pesadas a cada seis horas, quando se retirava uma amostra equivalente a $10 \%$ do peso total das fezes coletadas. As amostras foram armazenadas a $-18^{\circ} \mathrm{C}$ e, ao término de cada dia, foram homogeneizadas, quando se retirou uma amostra composta diária, que, em seguida, foi congelada.

As amostras compostas foram descongeladas à temperatura ambiente, pré-secas em estufa de ventilação forçada a $65^{\circ} \mathrm{C}$, por 72 horas, e, posteriormente moídas e acondicionadas em frascos plásticos identificados, para posterior análise bromatológica.

Nas amostras de feno, de aveia hidropônica, de ração concentrada e de fezes foram efetuadas análises para a determinação dos teores de matéria seca (MS), de matéria orgânica (MO), de proteína bruta (PB), de fibra em detergente neutro (FDN), de fibra em detergente ácido (FDA), de lignina (LIG) e de energia bruta (EB), segundo metodologia descrita por Silva (1990).

Os coeficientes de digestibilidade aparente dos nutrientes $(\mathrm{CD})$ foram calculados pela seguinte equação:

$$
\begin{gathered}
\mathrm{CD}=(\% \mathrm{MS} \times \% \text { nutriente na dieta })- \\
\frac{(\% \mathrm{MS} \times \% \text { nutriente nas fezes })}{(\% \mathrm{MS} \times \% \text { nutriente na dieta })}
\end{gathered}
$$

Schneider \& Flatt (1975)

Os valores médios dos parâmetros avaliados foram submetidos à análise de variância e as médias, comparadas pelo teste Tukey, a 5\% de probabilidade, por intermédio do programa SAEG - Sistema de Análises Estatísticas e Genéticas (UFV, 2000).

\section{Resultados e Discussão}

Os valores médios do peso vivo e do escore corporal dos animais durante o ensaio de desempenho são apresentados na Tabela 3. Não foram observadas diferenças significativas $(\mathrm{P}>0,05)$ no peso vivo e no escore corporal dos eqüinos, em função das dietas experimentais a que foram submetidos.

Os pesos médios dos animais foram de 410, 420 e $416 \mathrm{~kg}$, para os animais que consumiram as dietas I, II e III, respectivamente.

Os animais apresentaram, no início do ensaio, escore corporal de 4,3 $\pm 0,7$ e, ao término do período experimental, os escores foram de 4,0;4,3 e 4,4, para aqueles alimentados com ração peletizada com feno

Tabela 2 - Composição percentual dos ingredientes nas dietas, na base da matéria natural, teores de energia bruta $(E B)$ e percentuais de matéria seca (MS), de proteína bruta (PB), de extrato etéreo (EE), de fibra em detergente neutro (FDN) e de fibra em detergente ácido (FDA) nas dietas experimentais, na base da matéria seca

Table 2 - Percentual ingredients composition of diets, in natural matter, gross energy (GE) content and percentual of dry matter (DM), crude protein $(C P)$, ether extract (EE), neutral detergente fiber (NDF)

\begin{tabular}{|c|c|c|c|}
\hline \multirow[t]{2}{*}{$\begin{array}{l}\text { Itens } \\
\text { Items }\end{array}$} & \multicolumn{3}{|c|}{$\begin{array}{c}\text { Dietas } \\
\text { Diets }\end{array}$} \\
\hline & $\mathrm{I}$ & II & III \\
\hline $\begin{array}{l}\text { Feno de coastcross } \\
\text { Coastcrossgrass hay }\end{array}$ & 33,3 & 33,3 & 25,0 \\
\hline $\begin{array}{l}\text { Ração Hippus } \\
\text { Hippus ration }\end{array}$ & 66,7 & - & - \\
\hline $\begin{array}{l}\text { Ração Corcelina } \\
\text { Corcelina ration }\end{array}$ & - & 66,7 & 50,0 \\
\hline $\begin{array}{l}\text { Aveia hidropônica } \\
\text { Hydroponic oat }\end{array}$ & - & - & 25,0 \\
\hline $\begin{array}{l}\text { Total } \\
\text { Total } \\
\end{array}$ & 100 & 100 & 100 \\
\hline $\begin{array}{l}\mathrm{MS}(\%) \\
D M\end{array}$ & 91,3 & 91,2 & 71,6 \\
\hline $\begin{array}{l}\mathrm{PB}(\%) \\
C P\end{array}$ & 12,4 & 10,4 & 12,2 \\
\hline $\begin{array}{l}\mathrm{EB}(\mathrm{Mcal} / \mathrm{kg}) \\
G E\end{array}$ & 4,2 & 4,1 & 4,1 \\
\hline $\begin{array}{l}\mathrm{EE}(\%) \\
E E\end{array}$ & 3,3 & 3,3 & 3,2 \\
\hline $\begin{array}{l}\mathrm{FDN}(\%) \\
N D F\end{array}$ & 53,9 & 53,9 & 69,4 \\
\hline $\begin{array}{l}\text { FDA }(\%) \\
A D F\end{array}$ & 23,5 & 26,6 & 26,3 \\
\hline
\end{tabular}
and acid detergente fiber (ADF) in the experimental diets, in dry matter basis 
incorporado (dieta I), com ração peletizada (dieta II) e com ração peletizada acrescida de aveia hidropônica (dieta III).

A distribuição das médias dos pesos vivos dos animais submetidos às dietas experimentais encontrase na Figura 1. Os pesos médios mensais dos animais variaram, porém estas variações não foram significativas $(\mathrm{P}>0,05)$.

O escore corporal dos animais variou pouco entre os eqüinos, entretanto, para os animais que consumiram a dieta com ração peletizada, os valores médios mensais foram mais homogêneos, com menor variação na condição corporal (Figura 2).

Pipkin et al (1991), ao avaliarem eqüinos da raça Quarto de Milha com escore corporal médio de 6 e peso vivo em torno de $500 \mathrm{~kg}$, alimentados com dietas contendo volumoso (feno de alfafa) e concentrado em peletes ou separados, na proporção de volumoso e concentrado de 67:33, não observaram diferenças $(\mathrm{P}>0,10)$ no peso vivo e no escore corporal.

Os coeficientes de digestibilidade aparente estimados para matéria seca (CDMS), proteína bruta (CDPB), energia bruta (CDEB), fibra em detergente neutro (CDFDN) e fibra em detergente ácido (CDFDA) das três dietas estão na Tabela 4.

Foram observados valores inferiores $(\mathrm{P}<0,05)$ dos coeficientes de digestibilidade aparente de matéria seca (CDMS), de energia bruta (CDEB), de fibra em detergente neutro (CDFDN) e de fibra em detergente ácido (CDFDA) da dieta com ração peletizada acrescida de aveia hidropônica, quando comparados aos valores das dietas com ração peletizada com feno incorporado e com ração peletizada.

Em relação ao CDPB, o valor médio da dieta com ração peletizada com feno incorporado foi de $82,8 \%$, superior $(72,6 \%)$ aos das dietas com ração peletizada e com ração peletizada acrescida de aveia hidropônica.
As dietas I e II apresentaram melhores valores de digestibilidade, quandos comparadas à dieta III, para quase todos os nutrientes avaliados, o que pode ser decorrente do fato de a dieta III ter propiciado maior ingestão de alimento volumoso (aveia hidropônica) e, conseqüentemente, de mais fibra. Wolter (1975) argumenta que elevados níveis de fibra na dieta aumentam a motilidade intestinal e a velocidade de passagem da digesta, podendo reduzir a digestibilidade dos nutrientes.

Os coeficientes de digestibilidade aparente observados no presente trabalho foram superiores aos encontrados por Almeida (1994), em dietas mistas, de $58,7 \%$ para CDMS, $66,7 \%$ para CDPB, 58,4\% para CDEB, $45,9 \%$ para CDFDN e $37,3 \%$ para CDFDA.

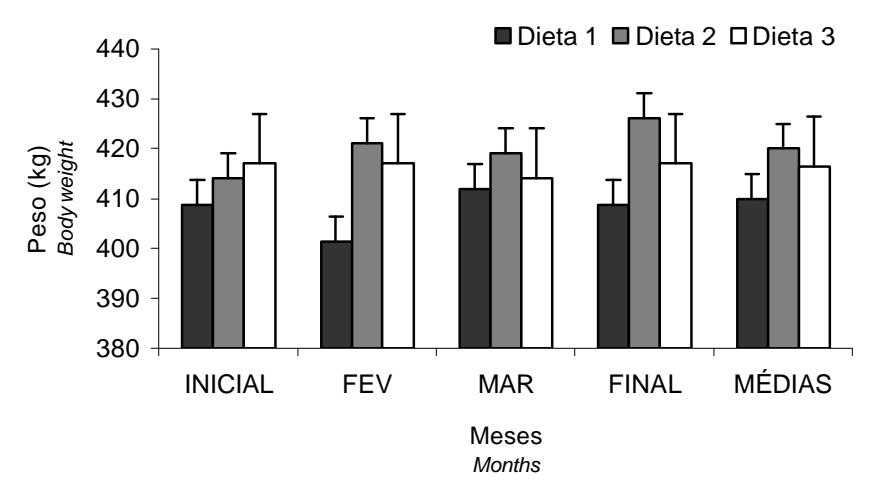

Figura 1 - Valores médios mensais do peso corporal dos eqüinos consumindo as dietas experimentais.

Figure 1 - Mean monthly values of body weight of horses fed experimental diets.

Tabela 3 - Valores médios do peso vivo e escore corporal de eqüinos consumindo as dietas experimentais

Tabela 3 - Average values of body weight and body score of horses fed experimental diets

\begin{tabular}{|c|c|c|c|c|c|c|c|c|c|}
\hline \multirow[b]{2}{*}{$\begin{array}{l}\text { Variáveis } \\
\text { Variables }\end{array}$} & \multicolumn{3}{|c|}{ Dieta I } & \multicolumn{3}{|c|}{ Dieta II } & \multicolumn{3}{|c|}{ Dieta III } \\
\hline & $\begin{array}{l}\text { Inicial } \\
\text { Initial }\end{array}$ & $\begin{array}{l}\text { Final } \\
\text { End }\end{array}$ & $\begin{array}{l}\text { Média } \\
\text { Mean }\end{array}$ & $\begin{array}{l}\text { Inicial } \\
\text { Initial }\end{array}$ & $\begin{array}{c}\text { Final } \\
\text { End }\end{array}$ & $\begin{array}{l}\text { Média } \\
\text { Mean }\end{array}$ & $\begin{array}{l}\text { Inicial } \\
\text { Initial }\end{array}$ & $\begin{array}{c}\text { Final } \\
\text { End }\end{array}$ & $\begin{array}{l}\text { Média } \\
\text { Mean }\end{array}$ \\
\hline $\begin{array}{l}\text { Peso }(\mathrm{kg}) \\
\text { Bodyweight }\end{array}$ & 409 & 409 & 410 & 414 & 426 & 420 & 417 & 417 & 416 \\
\hline $\begin{array}{l}\text { Escore corporal } \\
\text { Body score }\end{array}$ & 4,1 & 3,9 & 4,0 & 4,3 & 4,3 & 4,3 & 4,4 & 4,5 & 4,4 \\
\hline
\end{tabular}

R. Bras. Zootec., v.33, n.6, p.1492-1499, 2004 
As dietas com ração peletizada com feno incorporado e com ração peletizada, acrescidas de feno de capim coastcross apresentaram maiores valores de CDFDA que a dieta com ração peletizada acrescida de aveia hidropônica e de feno de capim coastcross, de 66,$2 ; 56,1$ e 44,3\%, respectivamente. O valor do CDFDA da dieta III foi superior ao valor médio de dietas mistas relatado por Almeida (1994).

Ao comparar os valores dos coeficientes de digestibilidade observados nas dietas I e II, cuja relação concentrado e volumoso foi de 66,7:33,3, com as dietas utilizadas por Manzano et al. (1980) (60:40), foram obtidos, no presente trabalho, valores de digestibilidade superiores para todos os nutrientes avaliados, o que pode estar relacionado com o tipo e qualidade de volumoso empregado na composição das dietas. Pereira et al. (1995), avaliando o feno de aveia em dietas com proporções de volumoso e concentrado de 100:0, 80:20, 60:40 e 40:60, registraram valor médio de CDMS de 62,4\%, inferior aos observados para as dietas avaliadas neste trabalho.

Os valores médios do consumo de nutrientes dos animais durante o ensaio de desempenho estão na Tabela 5 .

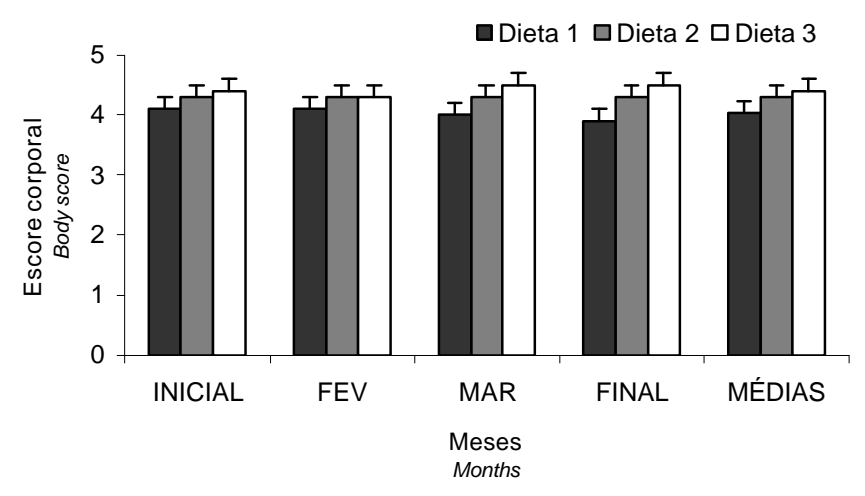

Figura 2 - Valores médios mensais do escore corporal dos animais consumindo as dietas experimentais.

Figure 2 - Mean monthly values of bodu score of horses fed experimental diets.
As proporções de concentrado e volumoso na base da MS foram de 66,7:33,3, nas dietas I e II, e de 64:36, na dieta III. O consumo de volumoso, na base da matéria seca, foi de $2,7 \mathrm{~kg}$, para as dietas I e II, e de 3,0 kg, para a dieta III, ressaltando-se que esta possuía uma fonte a mais de alimento volumoso (aveia hidropônica).

O consumo médio de matéria seca foi de $8,3 \mathrm{~kg} /$ dia para as dietas I e II e $8,6 \mathrm{~kg}$ para a dieta III, superior aos 7,8 kg recomendados pelo NRC (1989), para animais adultos com peso médio de $415 \mathrm{~kg}$, em trabalho muscular moderado. O consumo de matéria seca dos animais na dieta III foi levemente superior pelo fato de a aveia hidropônica ter sido acrescentada à dieta, aumentando o consumo de volumoso e de matéria seca total.

O consumo médio diário de proteína bruta nas dietas I, II e III foram de 1,07; 0,90 e 0,96 kg, valores acima do recomendado pelo NRC (1989) $(0,831 \mathrm{~kg}$ de $\mathrm{PB})$. O consumo médio diário de proteína digestível dos animais alimentados com a dieta I foi de $0,88 \mathrm{~kg}$, superior $(\mathrm{P}<0,05)$ ao daqueles que consumiram as dietas II $(0,71)$ e III $(0,69 \mathrm{~kg})$. Os animais que consumiram a dieta com ração peletizada acrescida

Tabela 4 - Valores médios dos coeficientes de digestibilidade aparente de matéria seca (CDMS), de proteína bruta (CDPB), de energia bruta (CDEB), de fibra em detergente neutro (CDFDN) e de fibra em detergente ácido (CDFDA) das dietas experimentais

Table 4 - Mean values of coefficients of apparent digestibility of dry matter (CADDM), crude protein (CADCP), gross energy (CADGE), neutral detergente fiber (CADNDF) and acid detergente fiber (CADADF) of experimental diets

\begin{tabular}{lccc}
\hline $\begin{array}{l}\text { Variável } \\
\text { Variable }\end{array}$ & \multicolumn{3}{c}{$\begin{array}{c}\text { Dietas } \\
(\text { Diets })\end{array}$} \\
\cline { 2 - 4 } & I & II & III \\
\hline CDMS $(\%)$ & $77,09^{\mathrm{a}}$ & $76,20^{\mathrm{a}}$ & $69,14^{\mathrm{b}}$ \\
$\begin{array}{l}C A D D M \\
\text { CDPB }(\%)\end{array}$ & $82,86^{\mathrm{a}}$ & $72,64^{\mathrm{b}}$ & $72,38^{\mathrm{b}}$ \\
$C A D C P$ & $77,21^{\mathrm{a}}$ & $75,79^{\mathrm{a}}$ & $69,10^{\mathrm{b}}$ \\
CDEB $(\%)$ & $71,20^{\mathrm{a}}$ & $70,99^{\mathrm{a}}$ & $62,02^{\mathrm{b}}$ \\
$C A D G E$ & $66,24^{\mathrm{a}}$ & $56,12^{\mathrm{a}}$ & $44,27^{\mathrm{b}}$ \\
CDFDN $(\%)$ & & & \\
$C A D N D F$ & &
\end{tabular}

Médias seguidas de letras distintas nas linhas diferem $(P<0,05)$ entre si pelo teste Tukey.

Mean followed by different letters in same line are different $(P<.05)$ by Tukey test.

R. Bras. Zootec., v.33, n.6, p.1492-1499, 2004 
de aveia hidropônica (dieta III) ingeriram menor quantidade de proteína digestível, mesmo com maior consumo de matéria seca.

A energia digestível consumida diariamente pelos animais foi de 26,85; 25,46 e 24,24 Mcal nas dietas I, II e III, respectivamente. Foi observada diferença significativa $(\mathrm{P}<0,05)$ nos valores de ED consumida na dieta com ração peletizada com feno incorporado (dieta I) em relação à dieta com ração peletizada acrescida de aveia hidropônica (dieta III), com valor intermediário apenas para a dieta com ração peletizada (dieta II). Os valores observados nas três dietas foram superiores ao valor prescrito pelo NRC (1989), de 20,7 Mcal/dia, para eqüinos com peso vivo semelhante e trabalho muscular moderado.

O NRC (1989) recomenda consumo diário de $40 \mathrm{~g}$ $\mathrm{PB} /$ Mcal ED, para eqüinos com peso médio semelhante e trabalho muscular moderado. A dieta

Tabela 5 - Valores médios do consumo de matéria seca (MS), de volumoso, de ração concentrada, de proteína bruta $(\mathrm{PB})$, de fibra em detergente neutro (FDN), de fibra em detergente ácido (FDA), de proteína digestível (PD) e de energia digestível (ED) das dietas experimentais, na base da matéria seca

Table 5 - Mean values of dry matter (DM), roughage, concentrate ration, crude protein $(C P)$ neutral detergente fiber (NDF), acid detergente fiber (ADF) digestible protein $(D P)$ and digestible energy $(D E)$ intake of the experimental diets, in dry matter basis

\begin{tabular}{|c|c|c|c|}
\hline \multirow[t]{2}{*}{$\begin{array}{l}\text { Consumo } \\
\text { Intake }\end{array}$} & \multicolumn{3}{|c|}{$\begin{array}{c}\text { Dietas } \\
\text { Diets }\end{array}$} \\
\hline & I & II & III \\
\hline MS Total (kg) & 8,20 & 8,20 & 8,60 \\
\hline Total DM & & & \\
\hline Volumoso (kg) & 2,70 & 2,70 & 3,00 \\
\hline Roughage & & & \\
\hline $\begin{array}{l}\text { Concentrado }(\mathrm{kg}) \\
\text { Concentrate }\end{array}$ & 5,50 & 5,50 & 5,50 \\
\hline $\mathrm{PB}(\mathrm{kg} / \mathrm{dia})$ & 1,07 & 0,91 & 0,96 \\
\hline$C P(\mathrm{~kg} / \mathrm{day})$ & & & \\
\hline $\begin{array}{l}\text { FDN (kg/dia) } \\
N D F(k g / d a y)\end{array}$ & 4,40 & 4,60 & 4,80 \\
\hline FDA (kg/dia) & 2,20 & 1,60 & 1,70 \\
\hline $\begin{array}{l}\text { ADF (kg/day) } \\
\mathrm{PD} \text { (kg/dia) }\end{array}$ & $0,88^{a}$ & $0,71^{\mathrm{b}}$ & $0,69^{\mathrm{b}}$ \\
\hline $\begin{array}{l}D P(\mathrm{~kg} / \mathrm{day}) \\
\mathrm{ED} \text { (Mcal/dia) } \\
D E(\text { Mcal/day) }\end{array}$ & $26,85^{\mathrm{a}}$ & $25,47^{\mathrm{ab}}$ & $24,24^{\mathrm{b}}$ \\
\hline
\end{tabular}

Médias seguidas de letras distintas nas linhas diferem $(P<0,05)$ entre si pelo teste Tukey.

Mean followed by different letters in same line are different $(P<.05)$ by Tukey test. com ração peletizada com feno incorporado apresentou relação de 39,9g PB/Mcal de ED consumida, semelhante à relação observada na dieta com ração peletizada acrescida de aveia hidropônica (39,6 g), enquanto, na dieta apenas com ração peletizada, a relação foi de $35,5 \mathrm{~g} \mathrm{PB/Mcal} \mathrm{de} \mathrm{ED}$ consumida.

Possivelmente, a menor variação de peso dos animais, apesar do maior consumo de nutrientes, decorre do fato de os animais estudados terem sido submetidos a estresse constante. Outro fator é que, apesar classificação do tipo do trabalho como moderado, sua intensidade variou de acordo com as necessidades das apresentações dos animais, sendo mais intenso na preparação para exibições mais freqüentes e menos intenso quando poucas exibições foram solicitadas.

O consumo diário de FDN dos animais submetidos à dieta I foi de $4,4 \mathrm{~kg}$, inferior ao daqueles alimentados com as dietas II $(4,6)$ e III $(4,8 \mathrm{~kg})$. Hintz (1994) sugere, como níveis mínimos nas dietas para eqüinos, $0,12 \mathrm{~kg}$ de fibra bruta/ $100 \mathrm{~kg}$ de peso vivo ou dietas com $20 \%$ de FDN ou $12 \%$ de FDA na dieta. No presente trabalho, as dietas I, II e III apresentaram percentuais de 53,8; 53,8 e 69,4\% de FDN e de 23,5; 26,6 e 26,3\% de FDA, respectivamente. Considerando o consumo de FDA diário, em função do peso vivo dos animais, observaram-se valores de 0,$53 ; 0,38$ e $0,41 \mathrm{~kg}$ de FDA/100 kg peso vivo, superiores aos valores mínimos recomendados por Hintz (1994).

\section{Conclusões}

Os animais alimentados com as dietas experimentais mantiveram o peso vivo e escore corporal inalterados pelas variações dos conteúdos de nutrientes nas mesmas. O escore corporal médio dos eqüinos em atividades militares foi de 4,0.

Os coeficientes de digestibilidade aparente foram alterados em função das dietas experimentais e, de acordo com os resultados observados, a dieta contendo ração comercial com feno incorporado ao pelete apresentou maior digestibilidade dos nutrientes.

O consumo de energia e de proteína digestível nas dietas avaliadas foi adequado às atividades militares e o consumo de fibra dietética, expressa em FDN e FDA, atendeu às exigências mínimas dos eqüinos. 


\section{Agradecimento}

À Agribrands Purina, pela concessão das rações concentradas, e ao Comandante Regimento Escola de Cavalaria Andrade Neves do Exército Brasileiro, Coronel Cavaleiro Marcus Gerson Cordeiro Vinhas, pela compreensão da importância e valorização da pesquisa.

\section{Literatura Citada}

ALMEIDA, M.I.V. Predição da energia digestível de dietas para eqüinos a partir de seu conteúdo fibroso. Universidade Federal de Minas Gerais, Belo Horizonte: 1994. 104p. Dissertação (Mestrado em Zootecnia) - Universidade Federal de Minas Gerais, 1994.

HENNEKE, D.R.; POTTER, G.D.; KREIDER, J.L. et al. Relationship between condition score, physical measurements and body fat percentage in mares. Equine Veterinary Journal, v.15, n. 4, p.897-903, 1983.

HINEY, H.M.; POTTER, G.D. A review of recent research on nutrition and metabolism in the atletic horse. Nutrition Research and Reviews, v.9, p.149-173, 1996.

HINTZ, H.F. Fiber for horses. Equine Practice, v.16, n.6, p.7-8, 1994.

HINTZ, H.F. Alimentando o cavalo atleta. Cadernos Técnicos da Escola de Veterinária-UFMG, n.19, p.49-57, 1997.

MANZANO, A.; NOVAES, N.J.; HADDAD, C.M. et al. Comparação entre coeficientes de digestibilidade de rações com feno de capim de Rhodes e capim elefante variedade napier verde picado em eqüinos. Revista da Sociedade Brasileira de Zootecnia, v.9, n.4, p.673-690, 1980.

MEYER, H. Alimentação de cavalos. São Paulo: Varela, 1995. $303 p$.
NATIONAL RESEARCH COUNCIL - NRC. Nutrient requirements of horses. 5.ed. Washington, D.C.: National Academy of Science, 1989. 100p.

PAGAN, J. D. Energy and the performance horses. In: PAGAN, J.D. (Ed.) Advances in equine nutrition I. Lexington: Kentucky Equine Research, 1998a. p.141-147.

PAGAN, J.D. Measuring the digestible energy content of horse feeds. In: PAGAN, J.D. (Ed.) Advances in equine nutrition I. Lexington: Kentucky Equine Research, 1998b. p.71-76.

PAGAN, J.D. Protein requirements and digestibility: a review. In: PAGAN, J.D. (Ed.) Advances in equine nutrition $I$. Lexington: Kentucky Equine Research, 1998c. p.43-50.

PEREIRA, J.C.; QUEIROZ A.C.; CARMO, M.B. Avaliação de métodos para determinação da digestibilidade aparente em eqüinos. Revista da Sociedade Brasileira de Zootecnia, v.24, n.3, p.382-390. 1995.

PIPKIN, J.L; YOSS, L.J.; RICHARDSON, C.R. et al. Total mixed ration for horses. In: EQUINE NUTRITION AND PHYSIOLOGY SIMPOSIUM, 11., 1991, Oklahoma. Proceedings... Oklahoma:ENPS. 1991, p.55-56.

SCHNEIDER, B.H.; FLATT, W.T. The evaluation of feeds through digestibility experiments. Athens, Georgia: The University of Georgia Press, 1975. 423p.

SILVA, D.J. Análise de alimentos (métodos químicos e biológicos). Viçosa, MG: Universidade Federal de Viçosa. 2.ed. $1990.166 \mathrm{p}$.

UNIVERSIDADE FEDERAL DE VIÇOSA - UFV. SAEG Sistema de análises estatísticas e genéticas. Viçosa, MG: Universidade Federal de Viçosa, 2000. Manual do usuário, 150p. (versão 8.0).

WOLTER, R. Alimentacion del caballo. 2.ed. Zaragoza: Acribia, 1975. 172p.

Recebido em: 02/05/03

Aceito em: 16/12/03 